\title{
PENGELOLAN STANDAR SARANA DAN PRASARANA JURUSAN MENJAHIT PADA LEMBAGA KURSUS DAN PELATIHAN (LKP) JAKARTA BARAT
}

\author{
Rosi Damawanti, Shinta Doriza, Agus Dudung \\ Pendidikan Kesejahteraan Keluarga Universitas Negeri Jakarta \\ rosidamawanti@gmail.com
}

\begin{abstract}
Abstrak :
Pengelolaan standar sarana dan prasarana jurusan menjahit pada lembaga kursus dan pelatihan (LKP) jakarta. penelitian ini memiliki tujuan untuk mengetahui standar pengelolaan lembaga kursus dan pelatihan (LKP) jurusan menjahit. Penelitian ini juga menggunakan metode kualitatif fenomenologi. Subjek dari penelitian ini adalah ketua jurusan dari jurusan menjahit. Teknik pengumpulan data dengan cara adalah observasi dan wawancara. standar pengelolaan sarana dan prasarana yang mencakup [1] perencanaan, [2] pengadaan, [3] penyimpanan, [4] pemeliharaan, [5] penghapusan sarana dan prasarana jurusan menjahit di LKP Jakarta Barat
\end{abstract}

Kata Kunci : pengelolaan standar sarana dan prasarana, lembaga kursus dan pelatihan (LKP)

\section{Abstract :}

Management of standard facilities and infrastructure for the sewing department at the Jakarta Course and Training Institute (LKP). This study aims to determine the management standards of course and training institutions (LKP) majoring in sewing. This study also uses a qualitative phenomenological method. The subject of this research is the head of the department of the sewing department. data collection techniques by means of observation and interviews. standard of facilities and infrastructure management which includes [1] planning, [2] procurement, [3] storage, [4] maintenance, [5] elimination of facilities and infrastructure for the sewing department at LKP Jakarta Barat

Keywords : standard management of facilities and infrastructure, course and training institutions (LKP)

\section{PENDAHULUAN}

Pendidikan merupakan suatu keharusan bagi manusia karena dengan pendidikan manusia dapat menambah pengetahuan,mengembangkan keterampilan serta dapat menghadapi tantangan di masa yang akan datang. Tujuan pendidikan nasional yaitu mengembangkan potensi peserta didik agar menjadi manusia yang beriman dan bertaqwa kepada Tuhan Yang Maha Esa, berakhlak mulia, berilmu, sehat, cakap, kreatif, mandiri, dan menjadi warga negara yang demokratis dan bertanggung jawab. Untuk mewujudkan tercapainya tujuan pendidikan nasional, maka kegiatan pendidikan dilaksanakan melalui tiga jalur, yaitu pendidikan formal, pendidikan nonformal dan pendidikan informal.Sebagaimana yang dijelaskan oleh Sudjana (Sutarto, dkk 2017: 22) lingkungan pendidikan dalam keluarga atau pendidikan informal merupakan kegiatan pendidikan yang berlangsung sepanjang hayat, dimana tiap-tiap orang 
memperoleh nilai,sikap keterampilan dan pengetahuan yang berasal dari pengalaman hidup sehari-hari dan dari pengaruh-pengaruh dan sumber-sumber pendidikan di dalam lingkungan hidupnya dari keluarga, tetangga, lingkungan permainan atau pekerjaan, pasar, perpustakaan, dan media masa. Pendidikan formal merupakan sistem pendidikan yang diselenggarakan oleh lembaga persekolahan yang dalam tindakan operasionalnya memiliki legalitas dan formalitas serta beberapa persyaratan yang harus dipenuhi (Sutarto, 2007: 8). Undang-Undang Nomor 20 Tahun 2003 tentang Sistem Pendidikan Nasional menyatakan bahwa pendidikan nonformal diselenggarakan bagi warga masyarakat yang memerlukan layanan pendidikan yang berfungsi sebagai pengganti, penambah, dan/atau pelengkap pendidikan formal dalam rangka mendukung pendidikan sepanjang hayat. Satuan pendidikan nonformal terdiri dari lembaga kursus, lembaga pelatihan, kelompok belajar, pusat kegiatan belajar masyarakat, dan majelis taklim serta satuanpendidikan lain yang sejenis. Salah satu upaya untuk meningkatkan kualitas sumber daya manusia, yaitu melalui kursus maupun pelatihan. Salah satu bentuk satuan pendidikan nonformal, yaitu Lembaga Kursus dan Pelatihan (LKP).

Standar sarana dan prasarana adalah standar nasional pendidikan yang berkaitan dengan kriteria minimal tentang ruang belajar, tempat berolahraga, tempat beribadah, perpustakaan, laboratorium, bengkel kerja, tempat bermain, tempat berkreasi dan berekreasi, serta sumber lain yang diperlukan untuk menunjang proses pembelajaran. Satuan pendidikan memiliki sarana yang meliputi perabotan, peralatan pendidikan, media pendidikan, buku dan sumber belajar lainnya, bahan habis pakai, serta perlengkapan lain yang diperlukan untuk menunjang proses pembelajaran yang teratur dan berkelanjutan dan memiliki prasarana meliputi lahan, ruang kelas, ruang pimpinan satuan pendidikan, ruang pendidik, ruang tata usaha, ruang perpustakaan, ruang laboratorium, ruang bengkel kerja, ruang unit produksi, ruang kantin, instalasi daya dan jasa, tempat berolahraga. (Muhyiddin, 2017: 2)

Menurut Peraturan Menteri Pendidikan dan Kebudayaan nomor 127 tahun 2014 tentang standar sarana dan prasarana LKP, prasarana yang terdiri dari lahan, dibuktikan dengan status kepemilikan dan luas lahan, bangunan dan gedung yang dilengkapi dengan izin mendirikan bagunan (IMB) dan luas bangunan, ruang pembelajaran yang meliputi ruang teori dan praktik, ruang penunjang yang meliputi sarana di ruang pimpinan, ruang instruksi, ruang administrasi, ruang baca, toilet, ruang penyimpanan/gedung, tempat parkir dan tempat ibadah. Sarana yang terdiri dari ruang pembelajaran teori yang meliputi sarana pembelajaran teori, bahan ajar teori, media pembelajaran teori, ruang pembelajaran praktik yang meliputi alat praktik yang meliputi alat peraga utama, alat peraga pendukung, peralatan pendukung, alat-alat ukur, alat-alat tangan, 
alat-alat khusus dan bahan ajar praktik, ruang penunjang yang meliputi meja, kursi, lemari dan alat kantor.

Pengelolaan standar sarana dan prasarana pendidikan adalah kegiatan yang mengatur untuk mempersiapkan segala peralatan/material bagi terselenggaranya proses pendidikan di sekolah. Pengelolaan standar sarana dan prasarana dibutuhkan untuk membantu kelancaran proses belajar mengajar. Sarana dan prasarana pendidikan adalah semua benda bergerak dan tidak bergerak yang dibutuhkan untuk menunjang penyelenggaraan kegiatan belajar mengajar, baik secara langsung maupun tidak langsung. (Manajemen Sekolah. Rohiat. 2010 : 26) Pengelolaan sarana dan prasarana merupakan keseluruhan proses perencanaan pengadaan, pendayagunaan, dan pengawasan sarana dan prasarana yang digunakan agar tujuan pendidikan di sekolah dapat tercapai dengan efektif dan efisien. Kegiatan manajemen sarana dan prasarana meliputi :

\section{Perencanaan}

Perencanaan merupakan suatu proses kegiatan menggambarkan sebelumnya hal-hal yang akan dikerjakan kemudian dalam rangka mencapai tujuan yang telah ditetapkan. Dalam hal ini perencanaan yang dimaksud adalah merinci rancangan pembelian, pengadaan, rehabilitasi, distribusi atau pembuatan peralatan dan perlengkapan sesuai dengan kebutuhan. Dengan demikian perencanaan sarana dan prasarana pendidikan dapat didefinisikan sebagai keseluruhan proses perkiraan secara matang rancangan pembelian, pengadaan, rehabilitasi, distribusi atau pembuatan peralatan dan perlengkapan yang sesuai dengan kebutuhan sekolah.

2. Pengadaan

Pengadaan merupakan serangkaian kegiatan menyediakan berbagai jenis sarana dan prasarana pendidikan sesuai dengan kebutuhan untuk mencapai tujuan pendidikan. Kebutuhan sarana dan prasarana dapat berkaitan dengan jenis spesifikasi, jumlah,waktu, tempat, harga serta sumber yang dapat dipertanggungjawabkan. Pengadaan dilakukan sebagai bentuk realisasi ats perencanaan yang telah dilakukan sebelumnya. Tujuannya untuk menunjang proses pendidikan agar berjalan efektif dan efisien sesuai dengan tujuan yang di inginkan.

3. Penyimpanan

Penyimpanan sarana dan prasarana adalah kegiatan yang dilakukan oleh satuan kerja atau petugas gudang untuk menampung hasil pengadaan barang atau bahan kantor baik berasal dari pembelian, instansi lain, atau diperoleh dari bantuan.

4. Pemeliharaan 
Pemeliharaan merupakan kegiatan penjagaan atau pencegahan dari kerusakan suatu barang, sehingga barang tersebut kondisinya baik dan siap digunakan. Pemeliharaan mencakup segala daya upaya yang terus menerus untuk mengusahakan agar peralatan tersebut tetap dalam keadaan baik. Pemeliharaan dimulai daripemakaian barang, yaitu dengan cara hati-hati dalam menggunakannya. Pemeliharaan yang bersifat khusus harus dilakukan oleh petugas yang mempunyai keahlian sesuai dengan jenis barang yang dimaksud

5. Penghapusan sarana dan prasarana pendidikan Penghapusan barang adalah kegiatan akhir dari siklus pengelolaan sarana dan prasarana yang dilakukan dengan menggunakan mekanisme tertentu, berdasarkan peraturan dan ketentuanyang berlaku. Tujuan penghapusan sarana dan prasarana adalah untuk membebaskan bendaharawan barang atau pengelola dari pertanggung jawaban administrasi dan fisik atas barang milik negara yang berada di bawah atau pengurusannya sesuai dengan perundang-undangan yang berlaku.

\section{METODE PENELITIAN}

Peneliti menggunakan penelitian kualitatif dengan interpretatif fenomenologi. Hal ini dikarenakan permasalahan yang dibahas akan menghasilkan data yang berupa kata-kata baik lisan maupun tertulis, berupa gambaran dan bukan angka-angka. Dengan pendekatan ini diharapkan temuan-temuan empiris dapat dideskripsikan secara lebih rinci, lebih jelas dan lebih akurat, terutama berbagai hal yang berkaitan dengan pelaksanaan kegiatan yang dilakukan sebagai upaya mendeskripsikan mengenai bagaimana standar sarana prasana yang tersedia di LKP Jakarta Barat. Teknik pengumpulan data melalui observasi dan wawancara.

\section{HASIL DAN PEMBAHASAN}

Berdasarkan dari data yang dihasilkan berkaitan dengan standar sarana dan prasarana yang ada di LKP Jakarta Barat, didapatkan hasil penelitian bahwa standar pengelolaan sarana dan prasarana yang mencakup [1] perencanaan, [2] pengadaan, [3] penyimpanan, [4] pemeliharaan, [5] penghapusan sarana dan prasarana jurusan menjahit di LKP Jakarta Barat. Perencanaan sarpras LKP Jakarta Barat dapat diartikan sebagai keseluruhan proses inventerisasi sarpras yang ada dan analisis kebutuhannya. Dalam menentukan kebutuhan diperlukan beberapa data diantaranya adalah jenis spesifikasi dan jumlah, sehingga kebutuhan disesuaikan dengan besaran pembiayaan dari dana yang tersedia. Pembiayaan ini merupakan proses yang melalui pengawasan yang akurat. 
Bafadal (2003:86-87) berpendapat bahwa secara umum tujuan manajemen sarana dan prasarana pendidikan adalah memberikan pelayanan secara profesional di bidang sarana dan prasarana pendidikan dalam rangka terselenggaranya proses pendidikan secara efektif dan efisien, sedangkan tujuan khususnya adalah:

1. Mengupayakan pengadaan sarana dan prasarana pendidikan melalui sistem perencanaan dan pengadaan yang hati-hati dan seksama. Melalui manajemen sarana dan prasarana pendidikan diharapkan semua perlengkapan yang didapatkan oleh sekolah adalah sarana dan prasarana yang berkualitas tinggi, sesuai dengan kebutuhan sekolah, dan dengan dana yang efisien.

2. Mengupayakan pemakaian sarana dan prasarana secara tepat dan efisien.

3. Mengupayakan pemeliharaan sarana dan prasarana sekolah, sehingga keberadaannya selalu dalam kondisi siap pakai dalam setiap diperlukan oleh semua personel sekolah.

LKP Jakarta Barat merupakan salah satu lembaga pendidikan non formal dibawah pemerintahan daerah, didalam LKP Jakarta Barat memiliki berbagai jurisan yang diantaranya adalah jurusan menjahit atau tata busana. Pengelolaan sarana prasarana memiliki masingmasing tugas untuk mengatur dan menjaga perlengkapan peralatan agar dapat memberikan optimalitas dalam membuat lingkungan yang bersih, rapi dan tersusun. Dalam pengelolaan sarana dan prasarana yang dilakukan LKP Jakarta Barat ini meliputi

1. Perencanaan Kebutuhan

Menurut Alder (1999) dalam Rustiadi (2008:339) menyatakan bahwa perencanaan merupakan suatu proses menentukan apa yang ingin dicapai pada masa atau suatu benda yang akan datang serta menetapkan tahapan-tahapan yang dibutuhkan untuk mencapainya. Perencanaan kebutuhan sarana dan prasarana berarti merinci rancangan pembelian, pengadaan, rehabilitasi atau pembuatan peralatan dan perlengkapan yang sesuai dengan kebutuhan sekolah. Dapat juga diartikan sebagai penyusunan keperluan perlengkapan di lembaga pendidikan yang didasarkan pada pertimbangan penyediaan barang disebabkan berkembangnya kebutuhan sekolah, pengadaan perlengkapan karena penggantian barang-barang yang rusak atau hilang juga untuk persediaan.Dalam pelaksanaan perencanaan kebutuhan sarana dan prasarana yang dilakukan LKP Jakarta Barat dapat dikatakan sudah cukup baik 
Kejuruan Garmen apparel.

Program pelatihan yang dapat dilaksanakan:

a. Pelatihan Menjahit pakaian dasar;

b. Pelatihan Pembuat baju kerja wanita;

c. Pelatihan Operator mesin bordir.

\begin{tabular}{|c|c|c|c|c|c|c|c|}
\hline $\begin{array}{l}\text { MESIN/PERALATAN } \\
\text { UTAMA DAN } \\
\text { PERLENGKAPANNYA }\end{array}$ & JUMLAH & $\begin{array}{l}\text { ALAT PERKAKAS } \\
\text { TANGAN } \\
\text { (HANDSTOOL DAN } \\
\text { POWERTOOL) }\end{array}$ & JUMLAH & ALAT KB & JUMLAH & $\begin{array}{l}\text { PERLENGKAPAN } \\
\text { PENDUKUNG }\end{array}$ & JUMLAH \\
\hline Mesin Jahit & 16 unit & Pendedel Jahitan & 16 buah & APAR & 2 buah & $\begin{array}{l}\text { Kotak } \\
\text { perlengkapan } \\
\text { menjahit }\end{array}$ & 16 buah \\
\hline Mesin Jahit Portabel & 8 unit & Gunting & 16 buah & Kotak P3K & 1 buah & $\begin{array}{l}\text { Workbench (meja } \\
\text { kerja untuk } \\
\text { gambar pola dan } \\
\text { potong bahan) }\end{array}$ & 1 buah \\
\hline Mesin Obras & 8 buah & Gunting Zig-zag & 16 buah & & & & \\
\hline $\begin{array}{l}\text { Mesin Jahit High } \\
\text { Speed }\end{array}$ & 8 unit & Gunting benang & 16 buah & & & & \\
\hline Mesin Bordir & 16 unit & $\begin{array}{l}\text { Dyna grip snape off } \\
\text { knife }\end{array}$ & 16 buah & & & & \\
\hline Mesin Pemotong Kain & 8 unit & Rader bergerigi & 16 buah & & & & \\
\hline Setrika Uap & 8 buath & Rader tanpa gerigi & 16 buah & & & & \\
\hline Meja Setrika & 8 buah & Pamindangan & 16 buah & & & & \\
\hline Penggaris tailor & 16 buah & & & & & & \\
\hline
\end{tabular}

Gambar 1.1 Standar peralatan untuk pemenuhan sarana dan prasarana LKP

\begin{tabular}{|l|l|l|l|l|l|l|l|}
\hline $\begin{array}{c}\text { MESIN/PERALATAN } \\
\text { UTAMA DAN } \\
\text { PERLENGKAPANNYA }\end{array}$ & JUMLAH & $\begin{array}{c}\text { ALAT PERKAKAS } \\
\text { TANGAN } \\
\text { (HANDSTOOL DAN } \\
\text { POWERTOOL) }\end{array}$ & JUMLAH & ALAT K3 & JUMLAH & $\begin{array}{c}\text { PERLENGKAPAN } \\
\text { PENDUKUNG }\end{array}$ & JUMLAH \\
\hline Penggaris pinggul & 16 buah & & & & & & \\
\hline Penggaris siku & 16 buah & & & & & & \\
\hline Penggaris lengan & 16 buah & & & & & & \\
\hline Penggaris jahit & 16 buah & & & & & & \\
\hline Meteran kain & 16 buah & & & & & \\
\hline
\end{tabular}

Gambar 1.2 Standar peralatan untuk pemenuhan sarana dan prasarana LKP

\section{Pengadaann}

Tahap selanjutnya adalah pengadaan, tahap ini merupakan tahap pemutusan segala kebutuhan dalam proses pembelajaran. Pengadaan sarana dan prasarana dapat diartikan sebagai segala kegiatan yang dilakukan dengan cara menyediakan perlengkapan dan prabot untuk menunjang kegiatan pembelajaran agar berjalan secara efektif dan efisien sesuai dengan tujuan yang diinginkan utnuk menyediakan perlengkapan. Jurusan menjahit juga sudah melakukan pengadaan terhadap sarana dan prasarana yang dilakukan dengan cara pemberian daftar yang sudah disiapkan, lalu diberikan kepada pimpinan LKP Jakarta Barat. Dalam hal ini ketua jurusan merupakan penangung jawab terhadap pengadaan sarana dan prasarana.

3. Penyimpanan 
Penyimpanan perlengkapan dan peralatan pendidikan adalah kegiatan menyimpan barang baik berupa prabot, alat tulis kantor, surat-surat maupun barang elektronik dalam keadaan baru ataupun sudah rusak yang dilakukan oleh seseorang atau beberapa orang yang telah ditunjuk atau ditugaskan pada lembaga pendidikan. Jurusan menjahit melakukan penyimpanan barang yang dimiliki seperti gunting, spidol, pulpen, benang tersimpan didalam rak kecil. Sedangkan untuk barang-barang besar seperti mesin jahit, meja, kursi, manakin, patung kepala diletakkan didalam laboratoorium atau ruang praktek. Kegiatan penyimpanan ini dilakukan dengan rapih dan diatur secara khusus sesuai dengan jenis dan kapasitasnya pada satu tempat tertentu di Jurusan menjahit ini.

4. Pemeliharaan

Pemeliharaan merupakan suatu perbuatan memelihara, memeriksa, merawat dan menyimpan barang yang sesuai dengan bentuk, jenis serta perawatan khusus setiap barang agar bertahan lama. Ketua, staff dan peserta didik jurusan menjahit terlibat dalam pemeliharaan saraa dan prasarana. Pemeliharaan sarana dan prasarana pendidikan di jurusan menjahit dimaksudkan untuk mengkondisikan peralatan tersebut senantiasa siap pakai dan tidakmengalami masalah ketika sedang dipergunakan. Jurusan menjahit melakukan kegiatan pemeliharaan terhadap sarana dan prasarana yang dimiliki dilakukan bersama-sama oleh pimpinan, instruktur maupun peserta didik.

5. Penghapusan

Penghapusan sarana dan prasarana merupakan kegiatan pembebasan sarana dan prasarana dari pertanggungjawaban yang berlaku dengan alasan yang dapat dipertanggungjawabkan. Secara lebih operasional penghapusan sarana dan prasarana adalah proses kegiatan yang bertujuan untuk mengeluarkan menghilangkan sarana dan prasarana dari daftar inventaris, karena sarana dan prasarana tersebut sudah dianggap tidak berfungsi sebagaimana yang diharapkan terutama untuk kepentingan pelaksanaan pembelajaran di jurusan menjahit. Adapun kegiatan penghapusan sarana dan prasarana yang dimiliki dengan cara menjual peralatan namun terdapat kekurangan dalam kegiatan tersebut yaitu belum melakukan pencatatan secara khusus mengenai penghapusan yang dilakukan.

\section{KESIMPULAN}

Perencanaan sarpras LKP Jakarta Barat dapat diartikan sebagai keseluruhan proses inventerisasi sarpras yang ada dan analisis kebutuhannya. Pembiayaan ini merupakan 
proses yang melalui pengawasan yang akurat. 1. Mengupayakan pengadaan sarana dan prasarana pendidikan melalui sistem perencanaan dan pengadaan yang hati-hati dan seksama. Pengelolaan sarana prasarana memiliki masing-masing tugas untuk mengatur dan menjaga perlengkapan peralatan agar dapat memberikan optimalitas dalam membuat lingkungan yang bersih, rapi dan tersusun. Dalam pengelolaan sarana dan prasarana yang dilakukan LKP Jakarta Barat ini meliputi . Menurut Alder (1999) dalam Rustiadi (2008:339) menyatakan bahwa perencanaan merupakan suatu proses menentukan apa yang ingin dicapai pada masa atau suatu benda yang akan datang serta menetapkan tahapan-tahapan yang dibutuhkan untuk mencapainya. Perencanaan kebutuhan sarana dan prasarana berarti merinci rancangan pembelian, pengadaan, rehabilitasi atau pembuatan peralatan dan perlengkapan yang sesuai dengan kebutuhan sekolah. Pengadaan sarana dan prasarana dapat diartikan sebagai segala kegiatan yang dilakukan dengan cara menyediakan perlengkapan dan prabot untuk menunjang kegiatan pembelajaran agar berjalan secara efektif dan efisien sesuai dengan tujuan yang diinginkan utnuk menyediakan perlengkapan. Penyimpanan perlengkapan dan peralatan pendidikan adalah kegiatan menyimpan barang baik berupa prabot, alat tulis kantor, surat-surat maupun barang elektronik dalam keadaan baru ataupun sudah rusak yang dilakukan oleh seseorang atau beberapa orang yang telah ditunjuk atau ditugaskan pada lembaga pendidikan. Jurusan menjahit melakukan penyimpanan barang yang dimiliki seperti gunting, spidol, pulpen, benang tersimpan didalam rak kecil. Pemeliharaan merupakan suatu perbuatan memelihara, memeriksa, merawat dan menyimpan barang yang sesuai dengan bentuk, jenis serta perawatan khusus setiap barang agar bertahan lama. Pemeliharaan sarana dan prasarana pendidikan di jurusan menjahit dimaksudkan untuk mengkondisikan peralatan tersebut senantiasa siap pakai dan tidakmengalami masalah ketika sedang dipergunakan. Penghapusan sarana dan prasarana merupakan kegiatan pembebasan sarana dan prasarana dari pertanggungjawaban yang berlaku dengan alasan yang dapat dipertanggungjawabkan.

\section{DAFTAR PUSTAKA}


Anonim.Undang-Undang Republik Indonesia Nomor 20 Tahun 2003 Tentang Sistem Pendidikan Nasional.

Bafadal, Ibrahim.2003. Manajemen Perlengkapan Sekolah Teori dan Aplikasinya.Jakarta: Bumi Aksara.

Eko, Triyanto.2013. Peran Kepala Sekolah dalam Pemanfaatan Media Pembelajaran Sebagai Upaya Peningkatan Kualitas Proses Pembelajaran.Jurnal Teknologi Pendidikan. Volume 1, No 2 Hal 226-238.

Nurbaiti. 2015. Manajemen Sarana Prasarana Sekolah. Jurnal Manajer Pendidikan Volume 9, Nomor 4 Hal 536-546.

Saputra, Bayu. 2015. Analisis Manajemen Sarana dan Prasarana. Skripsi Jurusan Administrasi Pendidikan Fakultas Ilmu Pendidikan. Bandung: Universita Pendidikan Indonesia.

Rohiat. (2010). Manajemen Sekolah. Bandung : PT Refika Aditama

Sulfemi, Wahyu Bagja dan Hilga Minati. (2018). Meningkatkan Hasil Belajar Peserta Didik Kelas 3 SD Menggunakan Model Picture And Picture dan Media Gambar Seri. JPSD. 4 (2), 228- 242. 